\title{
DegS and YaeL participate sequentially in the cleavage of RseA to activate the $\sigma^{\mathrm{E}}$-dependent extracytoplasmic stress response
}

\author{
Benjamin M. Alba, ${ }^{1,5}$ Jennifer A. Leeds, ${ }^{4,5,6}$ Christina Onufryk, ${ }^{1}$ Chi Zen Lu, ${ }^{3}$ \\ and Carol A. Gross ${ }^{2,3,7}$ \\ ${ }^{1}$ Department of Biochemistry and Biophysics, ${ }^{2}$ Department of Microbiology and Immunology, and ${ }^{3}$ Department \\ of Stomatology, University of California at San Francisco, San Francisco, California 94143, USA; ${ }^{4}$ Harvard Medical School, \\ Department of Microbiology and Molecular Genetics, Boston, Massachusetts 02115, USA
}

\begin{abstract}
All cells have stress response pathways that maintain homeostasis in each cellular compartment. In the Gram-negative bacterium Escherichia coli, the $\sigma^{\mathrm{E}}$ pathway responds to protein misfolding in the envelope. The stress signal is transduced across the inner membrane to the cytoplasm via the inner membrane protein RseA, the anti-sigma factor that inhibits the transcriptional activity of $\sigma^{\mathrm{E}}$. Stress-induced activation of the pathway requires the regulated proteolysis of RseA. In this report we show that RseA is degraded by sequential proteolytic events controlled by the inner membrane-anchored protease DegS and the membrane-embedded metalloprotease YaeL, an ortholog of mammalian Site-2 protease (S2P). This is consistent with the mechanism of activation of ATF6, the mammalian unfolded protein response transcription factor by Site-1 protease and S2P. Thus, mammalian and bacterial cells employ a conserved proteolytic mechanism to activate membrane-associated transcription factors that initiate intercompartmental cellular stress responses.
\end{abstract}

[Key Words: DegS; YaeL; regulated intramembrane proteolysis; $\sigma^{\mathrm{E}}$; ATF6; Site-2 protease]

Received May 20, 2002; revised version accepted June 21, 2002.

Stress response pathways that sense protein misfolding and other cellular damage in one compartment of the cell and transduce this signal to another cellular compartment are essential for balanced cell growth. Eukaryotic cells sense protein misfolding in the endoplasmic reticulum (ER) and transduce this signal to the nucleus of the cell to generate an appropriate response. This process has been called the unfolded protein response (UPR) (for review, see Patil and Walter 2001). Likewise, Gramnegative bacteria sense unfolded proteins in the envelope compartment of the cell and transduce this signal to the cytoplasmic compartment to generate a response. This process has been termed the extracytoplasmic stress response. In this report, we show that the $\sigma^{\mathrm{E}}$-dependent Escherichia coli extracytoplasmic stress response has a proteolytic regulatory element that is similar to that of the ATF6-dependent response of mammalian cells dur-

\footnotetext{
${ }^{5}$ These authors contributed equally to this work.

'Present address: Dyax Corp., 300 Technology Square, Cambridge, MA 02139, USA.

${ }^{7}$ Corresponding author.

E-MAIL cgross@cgl.ucsf.edu; FAX (415) 476-4204.

Article and publication are at http://www.genesdev.org/cgi/doi/10.1101/ gad.1008902.
}

ing the UPR (Ye et al. 2000) and the sterol regulatory element-binding protein (SREBP)-dependent response to sterol deprivation (Brown et al. 2000).

In mammals, the UPR is initiated in part by the processing of ATF6, an integral membrane protein with an $\mathrm{N}$-terminal, cytoplasmic basic leucine zipper (bZIP) transcription factor domain (Haze et al. 1999). The C-terminal domain of ATF6 projects into the ER and is positioned to sense stress in that cellular compartment (Haze et al. 1999). During ER stress, the bZIP domain is released by sequential proteolytic events controlled by the Site- $1(\mathrm{~S} 1 \mathrm{P})$ and Site-2 (S2P) proteases, which also process SREBPs in response to sterol deprivation (Rawson et al. 1997; Sakai et al. 1998; Ye et al. 2000). First, the membrane-anchored serine protease S1P cleaves ATF6 in its lumenal domain (Ye et al. 2000). For this cleavage event to occur, ATF6 must transit to a post-ER compartment in or near the Golgi complex where S1P and S2P are active (DeBose-Boyd et al. 1999; Ye et al. 2000; Chen et al. 2002). Following S1P cleavage, the remaining integral membrane fragment of ATF6 becomes a substrate for regulated intramembrane proteolysis (RIP) by S2P, an integral membrane metalloprotease that cleaves ATF6 within its membrane-spanning region (Ye et al. 2000). 
The released N-terminal domain travels to the nucleus where it activates transcription of chaperone-encoding genes and other key regulators of the response (Haze et al. 1999).

The extracytoplasmic stress response in E. coli is induced by excessive amounts of unfolded proteins in the envelope of the cell, particularly unfolded outer membrane porins, which are an abundant component of the outer membrane of Gram-negative bacteria (Mecsas et al. 1993; Betton et al. 1996; Missiakas et al. 1996; Rouvière and Gross 1996; Jones et al. 1997). This response is initiated by activating the transcription factor $\sigma^{\mathrm{E}}$, an alternative $\sigma$ factor that is required not only for the stress response but is also essential for $E$. coli viability under normal conditions (De Las Peñas et al. 1997b). $\sigma^{\mathrm{E}}$ directs the expression of genes encoding envelope-localized chaperones, protein folding catalysts, and proteases, as well as genes involved in lipid and lipopolysaccharide metabolism and cell wall biogenesis (Dartigalongue et al. 2001a; V. Rhodius, W. Suh, S. Ades, C. Onufryk, M. Igo, and C.A. Gross, in prep).

Under nonstress conditions, the activity of $\sigma^{\mathrm{E}}$ is negatively regulated by two proteins, RseA and RseB, which are encoded along with $r p o E\left(\sigma^{\mathrm{E}}\right.$ gene $)$ in a single operon. RseA, an inner membrane protein with one transmembrane domain, a cytoplasmic and a periplasmic domain, is the major negative regulator of $\sigma^{\mathrm{E}}$ (De Las Peñas et al. 1997a; Missiakas et al. 1997). The N-terminal cytoplasmic domain of RseA is an anti-sigma factor that binds to cytoplasmic $\sigma^{\mathrm{E}}$ and is sufficient to inhibit $\sigma^{\mathrm{E}}$ in vivo and in vitro (De Las Peñas et al. 1997a; Missiakas et al. 1997). The C-terminal domain of RseA projects into the periplasm and is positioned to sense stress in the envelope compartment (De Las Peñas et al. 1997a; Missiakas et al. 1997). This periplasmic domain of RseA interacts with RseB, an auxiliary negative regulator that may act as a sensor of unfolded proteins (De Las Peñas et al. 1997a; Missiakas et al. 1997; Collinet et al. 2000). When $E$. coli is subjected to heat shock, or when the outer membrane porin OmpC is overproduced, RseA is rapidly degraded (Ades et al. 1999). This frees $\sigma^{\mathrm{E}}$ to associate with RNA polymerase and direct the transcription of its regulon.

As the proteolysis of RseA is the central point of regulation in the $\sigma^{\mathrm{E}}$ pathway, we have been identifying proteins required for RseA degradation (Ades et al. 1999). We found that DegS, an inner membrane protease that is a member of the large DegP/HtrA family of serine proteases (Waller and Sauer 1996; Pallen and Wren 1997), is required for RseA degradation (Ades et al. 1999; Alba et al. 2001). Like $\sigma^{\mathrm{E}}$, DegS is required for viability (Alba et al. 2001). The essential function of DegS is to provide $\sigma^{\mathrm{E}}$ activity through the degradation of RseA, as $\operatorname{degS}$ null mutants are viable both in suppressor strains that no longer require $\sigma^{\mathrm{E}}$ activity for cell growth at low temperature and in strains lacking the negative regulator RseA (De Las Peñas et al. 1997b; Alba et al. 2001). In suppressor strains carrying a deletion of $\operatorname{degS}$ or a mutation in the DegS active site serine, RseA is not degraded and $\sigma^{\mathrm{E}}$ activity is not increased during inducing conditions
(Ades et al. 1999). Thus, in the absence of DegS, $\sigma^{\mathrm{E}}$ is almost fully inhibited by RseA (Ades et al. 1999; Alba et al. 2001). Because its proteolytic domain is periplasmically localized, DegS is likely to initiate degradation in the periplasmic domain of RseA (Alba et al. 2001). However, since the cytoplasmic domain of RseA alone is sufficient to inhibit $\sigma^{\mathrm{E}}$ activity (De Las Peñas et al. 1997a; Missiakas et al. 1997), it must also be degraded to release $\sigma^{\mathrm{E}}$ (Ades et al. 1999). Either DegS or other proteases working in coordination with DegS must perform this function (Alba et al. 2001). We took a candidate approach to look for other E. coli proteases that participate in RseA degradation.

We examined the involvement of YaeL, which is an inner membrane protein and an S2P ortholog, in RseA degradation (Lewis and Thomas 1999; Rudner et al. 1999; Kanehara et al. 2001). YaeL possesses the conserved signature amino acids of proteases that carry out RIP (Lewis and Thomas 1999; Rudner et al. 1999; Brown et al. 2000; Kanehara et al. 2001). YaeL is essential for cell growth (Dartigalongue et al. 2001a; Kanehara et al. 2001) and is a member of the $\sigma^{\mathrm{E}}$ regulon (Dartigalongue et al. 2001a; V. Rhodius, W. Suh, S. Ades, C. Onufryk, M. Igo, and C.A. Gross, in prep.). In the present study, we obtained evidence supporting a role for YaeL, along with DegS, in the sequential cleavages of RseA. Thus, activation of the E. coli extracytoplasmic stress response, like activation of ATF6 in the mammalian UPR, requires cleavage first by a membrane-anchored serine protease and subsequently by a membrane-embedded metalloprotease, to release the active transcription factor. YaeL joins a growing list of bacterial S2P orthologs that play important regulatory roles. These proteases include SpoIVFB, which is required to process the Bacillus subtilis sporulation factor $\sigma^{\mathrm{K}}$ to its active form (Rudner et al. 1999; Yu and Kroos 2000), and Eep, which is required to produce an eight-amino-acid pheromone in Enterococcus faecalis (Dunny and Leonard 1997; An et al. 1999; Brown et al. 2000).

\section{Results}

$\sigma^{E}$ activity decreases during depletion of YaeL

We tested whether YaeL plays a regulatory role in the extracytoplasmic stress response pathway by depleting YaeL in vivo and assaying $\sigma^{\mathrm{E}}$ activity with a reporter construct. This reporter contains a minimal $\sigma^{\mathrm{E}}$ promoter driving expression of $1 a c Z$ and has been extensively utilized to monitor $\sigma^{\mathrm{E}}$ activity (Mecsas et al. 1993; Ades et al. 1999). The construct is carried by a $\lambda$ phage located at the $\lambda$ attachment site in the chromosome. We grew the YaeL depletion strain (CAG43509), which has a chromosomal yaeL::kanR and a plasmid carrying wild-type (wt) $y a e L$, to midexponential growth phase in rich medium supplemented with arabinose. The addition of arabinose is required to induce the complementing copy of yaeL which is under the control of the $\mathrm{P}_{\text {ara }}$ promoter. Following growth, cells were collected, washed, and resus- 
Alba et al.

pended in rich medium containing arabinose or the $\mathrm{P}_{\text {ara }}$ repressor glucose. We maintained the cultures in midexponential growth phase by diluting the cultures with prewarmed media. Growth curves for each successive subculture are shown in Figure 1A. We observed that cells grown in the presence of glucose eventually cease growing and lyse, as described previously (Kanehara et al. 2001). The differential rate of $\beta$-galactosidase synthesis (the measure of $\sigma^{\mathrm{E}}$ activity) for each successive subculture in glucose, shown in Figure $1 \mathrm{~B}$, indicates that $\sigma^{\mathrm{E}}$ activity began to decrease starting in the third subculture. Notably, $\sigma^{\mathrm{E}}$ activity (Fig. 1B) decreased prior to the decrease in growth rate, which was not apparent until the fourth subculture (Fig. 1A). In contrast, $\sigma^{\mathrm{E}}$ activity in the arabinose-containing culture did not change (Fig. 1A; data not shown). We confirmed that the YaeL protein level decreased during the course of depletion (Fig. 1C) and remained constant under inducing conditions (data not shown). We note that in longer exposures of the Western blot (data not shown), YaeL remains detectable until the end of glucose subculture \#2, which is consistent with the decrease in $\sigma^{\mathrm{E}}$ activity during subculture \#3 (Fig. 1B). The data in Figure 1 were obtained in strain MC1061; similar data were obtained in strain MG1655 (data not shown). Together, these data suggest that YaeL is an activator of the $\sigma^{\mathrm{E}}$ pathway.

The essential function of YaeL is to maintain $\sigma^{E}$ activity $\sigma^{\mathrm{E}}$ activity is essential for E. coli viability (De Las Peñas et al. 1997b). Because $\sigma^{\mathrm{E}}$ activity decreases upon YaeL depletion, we considered the possibility that the essential function of YaeL is to maintain $\sigma^{\mathrm{E}}$ activity. If this

A
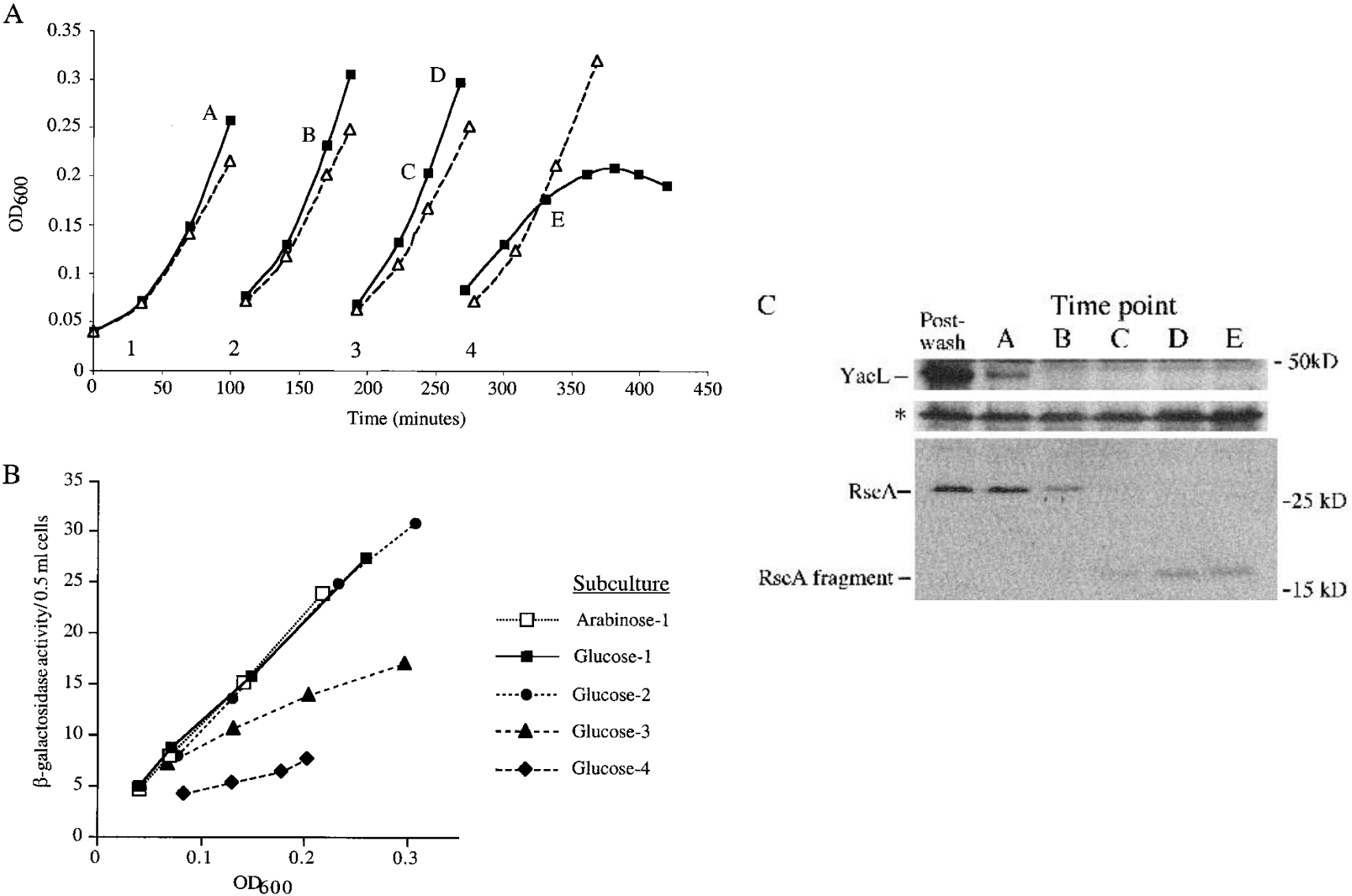

Figure 1. In vivo depletion of YaeL. $(A)$ Growth of YaeL depletion strain (CAG43509) in yaeL-inducing (LB/0.2\% arabinose; $\triangle$ ) or repressing $(\mathrm{LB} / 0.2 \%$ glucose; $\mathbf{0})$ media at $30^{\circ} \mathrm{C}$. The depletion strain carries yaeL::kanR on its chromosome and a complementing plasmid encoding yaeL expressed from an arabinose-inducible promoter $\mathrm{P}_{\text {ara }}$. The depletion was performed as described in Materials and Methods. To maintain the cultures in exponential phase, they were subcultured by dilution into the same prewarmed media. Numbers 1-4 designate the subcultures, and letters A-E identify the time points at which samples for Western blotting were removed. $(B) \sigma^{\mathrm{E}}$ activity during YaeL depletion. Samples from the LB/glucose and LB/arabinose subcultures in $(A)$ were assayed for $\sigma^{\mathrm{E}}$ activity by monitoring $\beta$-galactosidase activity produced from a single-copy [ $\Phi \lambda r p o H$ P $3:$ :lacZ] fusion. For simplicity, only $\sigma^{\mathrm{E}}$ activity from the first arabinose subculture is shown, because all subsequent arabinose subcultures had equivalent activities. Assays were performed as described in Materials and Methods. $(C)$ In vivo steady-state levels of YaeL, RseA, and RseA fragment during depletion. At the time points identified in $(A)$, samples were removed from the subcultures and analyzed by Western blotting using anti-YaeL and anti-RseA cytoplasmic domain antisera (see Materials and Methods). Asterisk indicates a nonspecific background band which controls for loading error. 
were true, then yaeL would not be essential in suppressor strains that no longer require $\sigma^{\mathrm{E}}$ activity for cell growth at low temperature (hereafter called sup ${ }^{+}$strains and described in De Las Peñas et al. 1997b). Consistent with this idea, yaeL::kanR could be moved into the sup ${ }^{+}$ background but not into the isogenic wt strain using P1 phage-mediated transduction (Table 1). Likewise, we could transduce yaeL::kanR into $\Delta \operatorname{deg} S$, which also harbors a suppressor that bypasses the need for $\sigma^{\mathrm{E}}$ activity in E. coli (Alba et al. 2001). Because YaeL is likely to function as a protease, it might increase $\sigma^{\mathrm{E}}$ activity by participating in the degradation of RseA. If so, yaeL should not be essential in strains lacking $r s e A$, as such strains have high, constitutive $\sigma^{\mathrm{E}}$ activity. This hypothesis is supported by results presented in Table 1. yaeL::kanR also could be transduced into a wt $E$. coli background that bypassed the need for RseA degradation because $\sigma^{\mathrm{E}}$ was overexpressed (Table 1).

We reconstructed the YaeL depletion system in the $\Delta r s e A$ strain, the sup ${ }^{+}$strain, and $\Delta d e g S$ strain (with its associated suppressor of $\sigma^{\mathrm{E}}$ essentiality) and then determined their efficiencies of plating (EOP) on Luria-Bertani (LB) medium in the absence of YaeL (LB/-arabinose) versus the presence of YaeL (LB/+arabinose). This allowed us to quantify the extent to which such genetic backgrounds dispensed with the need for YaeL (Table 2). The $\Delta r s e A$ and $\Delta d e g S$ strains efficiently bypassed the need for YaeL at all temperatures tested, exhibiting EOP values around 1 . The sup ${ }^{+}$strain efficiently bypassed the need for YaeL at $30^{\circ} \mathrm{C}$ and $37^{\circ} \mathrm{C}$, but not at $42^{\circ} \mathrm{C}$. This was expected because sup ${ }^{+}$does not efficiently bypass the need for $\sigma^{\mathrm{E}}$ at $42^{\circ} \mathrm{C}$ (De Las Peñas et al. 1997b). In sharp contrast, the EOP following YaeL depletion in the wt MC1061 background was $10^{-4}-10^{-3}$ at each temperature tested (Table 2). These data indicate that the essential function of YaeL is efficiently bypassed either by removing the need for $\sigma^{\mathrm{E}}$ activity or by removing the requirement for RseA proteolysis to generate $\sigma^{\mathrm{E}}$ activity. Our results support the model that the essential function of YaeL is to provide the cell with $\sigma^{\mathrm{E}}$ activity through the proteolysis of RseA.

Table 1. P1 transduction of yaeL :: kanR into E. coli strains grown on $L B$ at $30^{\circ} \mathrm{C}$

\begin{tabular}{lcc}
\hline & $\begin{array}{c}\text { \# } \mathrm{Kan}^{\mathrm{R}} \text { colonies obtained } \\
\text { following transduction with } \\
\text { P1 grown on donor strain } \\
\text { RaeL }:: \text { kanR }^{\mathrm{a}}\end{array}$ \\
\hline Wild-type & CAG16037 & 0 \\
$\Delta r s e A$ & CAG22968 & $\sim 100-150$ \\
sup ${ }^{+}$of $\Delta r p o E$ & CAG41001 & $\sim 100$ \\
$\Delta d e g S^{\mathrm{b}}$ & CAG33315 & $\sim 100-150$ \\
prpoE & CAG25187 & 0 \\
$0 \mathrm{mM} \mathrm{IPTG}$ & & $\sim 100$ \\
$0.1 \mathrm{mM}$ IPTG & & \\
\hline
\end{tabular}

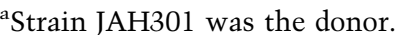

${ }^{\mathrm{b}}$ Contains a suppressor of $\Delta$ degS lethality.

$\mathrm{P} 1$ transductions were done twice and performed as described in Materials and Methods.
}

Table 2. Efficiencies of plating (EOP) of YaeL depletion strains in the absence (complementing yaeL repressed) versus the presence of arabinose (complementing yaeL induced) at $30^{\circ} \mathrm{C}, 37^{\circ} \mathrm{C}$, and $43^{\circ} \mathrm{C}$

\begin{tabular}{lcccc}
\hline & & \multicolumn{3}{c}{$\begin{array}{c}\text { Efficiencies of plating } \\
\text { (\#cfu } \\
\text { \#cfu + arabinose/ }\end{array}$} \\
\cline { 3 - 5 } Background & Strain & $30^{\circ} \mathrm{C}$ & $37^{\circ} \mathrm{C}$ & $43^{\circ} \mathrm{C}$ \\
\hline Wild type & CAG43509 & $1.2 \times 10^{-4}$ & $1.9 \times 10^{-3}$ & $5.7 \times 10^{-4}$ \\
$\Delta r s e A$ & CAG43550 & 1.7 & 1.2 & 0.6 \\
sup $^{+}$of $\Delta r p o E$ & CAG43549 & 0.8 & 0.4 & $8.6 \times 10^{-4}$ \\
$\Delta d e g S^{b}$ & CAG43560 & 0.9 & 0.6 & 0.9 \\
\hline
\end{tabular}

${ }^{\mathrm{a} C}$ Colony-forming units.

${ }^{\mathrm{b} C o n t a i n s}$ a suppressor of $\Delta d e g S$ lethality.

EOP were performed as described in Materials and Methods. Average EOP values are shown.

We previously showed that sup $^{+}$strains having either a $\Delta$ degS allele or expressing DegS S201A (which alters the protease active site serine to alanine) exhibited reduced basal $\sigma^{\mathrm{E}}$ activity and were unable to induce $\sigma^{\mathrm{E}}$ activity in response to the overexpression of OmpC (Ades et al. 1999). If YaeL also functions in RseA degradation, then E. coli carrying the null yaeL allele or expressing YaeL E23A (which alters the protease active site glutamic acid to alanine) should exhibit the same phenotypes. sup $^{+}$strains harboring the yaeL::kanR allele (data not shown) or expressing YaeL E23A in an otherwise null yaeL background exhibit lower basal $\sigma^{\mathrm{E}}$ activity than one expressing wt YaeL (Fig. 2). This reduction in basal activity is similar to that exhibited by sup $^{+}$ strains with a $\Delta \operatorname{deg} S$ allele or DegS S201A. Additionally, the uncomplemented yaeL::kanR strain (data not shown) and the yaeL::kanR strain expressing YaeL E23A were unable to induce $\sigma^{\mathrm{E}}$ activity in response to the overexpression of OmpC (Fig. 2). A Western blot confirmed that the steady-state level of YaeL E23A was at least as high as that of wt YaeL (data not shown). These results support the hypothesis that the proteolytic activity of YaeL is required for both basal and induced $\sigma^{\mathrm{E}}$ activity.

In addition to the nonconserved E23A substitution, we tested a conserved YaeL active site substitution (E23D) for its effect on YaeL activity. For two YaeL orthologs, mammalian S2P and B. subtilis SpoIVFB, changing the active site glutamic acid residue to aspartic acid $(\mathrm{E} \rightarrow \mathrm{D})$ does not abolish activity, although in other metalloproteases such a substitution is not tolerated (Rawson et al. 1997; Rudner et al. 1999|. We found that the yaeL::kanR mutant expressing YaeL E23D was able to induce the $\sigma^{\mathrm{E}}$ pathway when OmpC was overproduced (Fig. 2). By comparison, the S2P E172D mutant exhibited an activity only slightly lower than wt S2P (Rawson et al. 1997). Thus, the YaeL-like metalloproteases tested to date can tolerate the $\mathrm{E} \rightarrow \mathrm{D}$ substitution, most likely because the carboxylic acid group of aspartic acid can functionally substitute for that of glutamic acid (Rawson et al. 1997; Rudner et al. 1999). 
Alba et al.

Figure 2. Wild-type YaeL and YaeL E23D, but not the active-site mutant YaeL E23A, restore $\sigma^{\mathrm{E}}$ activity to a yaeL::kanR strain. sup $^{+}$yaeL ::kanR strains carrying pompC and pJAH322 (yaeL; $\mathbf{\square} \square$, CAG43540) or pJAH340 (yaeL E23A; $/ O$, CAG43541) or pJAH325 (yaeL E23D; $\mathbf{\Delta} \triangle \triangle$, CAG43553) were assayed for basal and induced $\sigma^{\mathrm{E}}$ activity by monitoring $\beta$-galactosidase

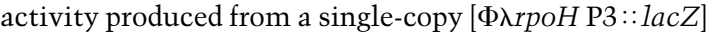
fusion, as described in Materials and Methods. The $\sigma^{\mathrm{E}}{ }_{-}$ inducing signal was provided by overexpressing OmpC with $0.2 \%$ arabinose, which was added immediately following the first assay time point $\left(\mathrm{OD}_{600} \sim 0.15\right)$. Solid symbols indicate the $\beta$-galactosidase activity of strains growing in the presence of arabinose (and, hence, overexpressing $\mathrm{OmpC}$ ); open symbols indicate the $\beta$-galactosidase activity of strains growing in the absence of arabinose (without OmpC overexpression). The inset shows the very low $\beta$-galactosidase activity of the yae $L$ E23A strain.

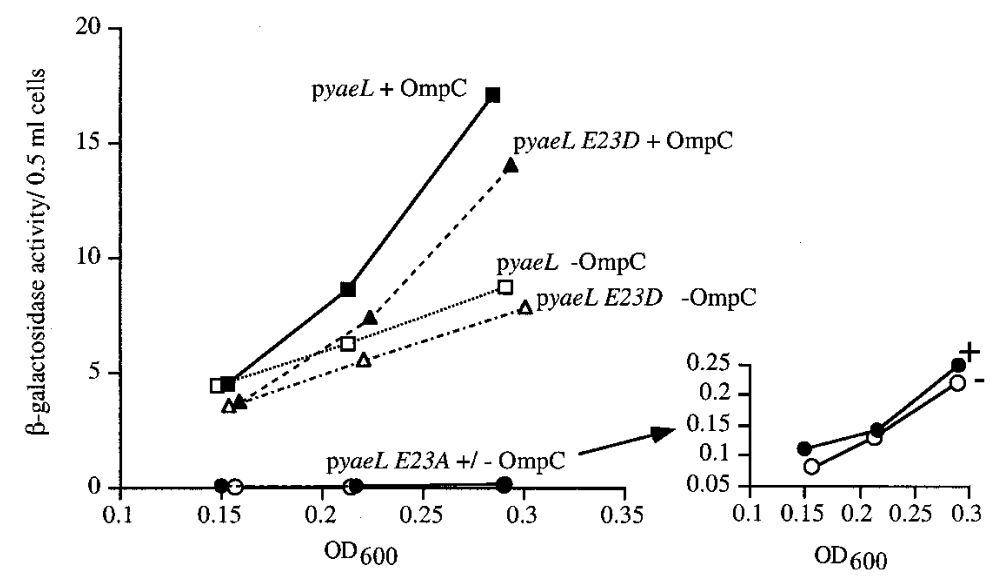

YaeL functions downstream of DegS in the RseA proteolytic pathway

length RseA with or without OmpC overexpression (Fig. $3 \mathrm{~B}$ ), and $\sigma^{\mathrm{E}}$ activity did not increase after OmpC overexpression (data not shown). These results are consistent with the model that RseA is processed sequentially, first Because DegS has an active site in the periplasm and is required for any proteolysis of RseA (Ades et al. 1999; Alba et al. 2001), we suspected that DegS-dependent processing would remove the periplasmic portion of RseA, allowing subsequent cleavage by YaeL. If so, strains lacking YaeL should accumulate an RseA fragment which contains the transmembrane and cytoplasmic domains. The results of the following series of experiments support this idea.

We used Western blotting to investigate whether a fragment containing the cytoplasmic domain of RseA accumulates in strains lacking active YaeL. We analyzed the strains without and with OmpC overexpression, the $\sigma^{\mathrm{E}}$-inducing signal. Strains expressing YaeL E23A (Fig, 3A, lanes 3,4) but not wt YaeL (Fig. 3A, lanes 1,2) exhibited high levels of an RseA fragment that was reactive to antisera against the cytoplasmic domain of RseA (Fig. 3A, lanes 3,4), but not the periplasmic domain of RseA (data not shown). With OmpC overexpression in the YaeL E23A background, the fragment accumulated to an even higher level, while the level of full-length RseA dropped to a low level (Fig. 3A, lane 4). The fragment still retained its anti-sigma factor activity since $\sigma^{\mathrm{E}}$ activity is not induced by OmpC overexpression (Fig. 2). The level of RseA after OmpC overexpression in cells expressing wt YaeL (lane 2) was as expected from previous studies (Ades et al. 1999). The low level of full-length RseA in the YaeL E23A background after OmpC expression (lane 4) is likely a consequence of its conversion to the RseA fragment and the reduced expression of $r s e A$ from the $\sigma^{\mathrm{E}}$ operon. This same fragment was produced in reduced amounts in strains expressing the YaeL E23D variant (with or without OmpC overexpression), which suggests that the E23D substitution, although conservative, slightly impairs the proteolytic activity of YaeL (Fig. 3A, lanes 5,6). As expected, DegS-dependent cleavage of RseA is a prerequisite for cleavage by $\mathrm{YaeL}$, because strains lacking both $\operatorname{degS}$ and yaeL exhibited only fullby DegS and then by YaeL.

The model describing sequential processing would be strengthened if we could demonstrate a precursor-product relationship between full-length RseA and the RseA fragment present in cells lacking YaeL activity. When
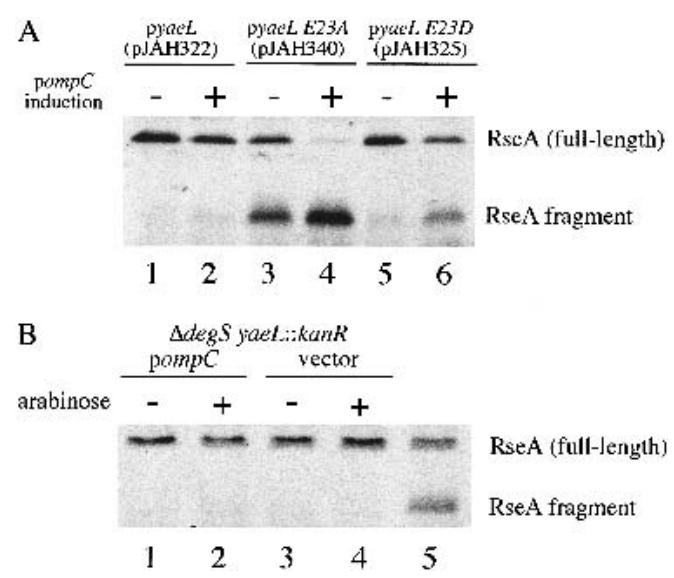

Figure 3. YaeL is involved in degradation of RseA. (A) Western blotting (with anti-RseA cytoplasmic domain) of samples harvested from sup ${ }^{+}$yaeL::kanR strains carrying pompC and pJAH322 (yaeL; lanes 1,2) or pJAH340 (yaeL E23A; lanes 3,4) or pJAH325 (yaeL E23D; lanes 5,6) grown with or without overexpression of OmpC for $60 \mathrm{~min}$. These samples are from the strains assayed for $\sigma^{\mathrm{E}}$ activity in Fig. 2. (B) Western blotting (with anti-RseA cytoplasmic domain) of samples harvested from $\Delta$ degS yaeL::kanR strains with pompC (lanes 1,2; CAG43551) or empty vector (lanes 3,4; CAG43552). Lane 5 shows a reference sample containing both full-length RseA and the RseA fragment. In both panels $A$ and $B$, arabinose was added to induce the overexpression of OmpC (see Materials and Methods). Cell fractionation experiments confirmed that overexpressed OmpC was present in the outer membrane fraction of the $\Delta$ degS yaeL::kanR strain carrying pompC (data not shown). 
the inducing signal caused by OmpC overexpression was provided to cells carrying YaeL E23A and active DegS, full-length RseA was virtually absent after $60 \mathrm{~min}$, and the RseA fragment is pronounced (Fig. 3A, lane 4). To quantify this conversion, we performed quantitative Western blotting at various timepoints following induction. These data demonstrate that as full-length RseA disappeared, the RseA fragment accumulated (Fig. 4A), with nearly all of the cytoplasmic domain from fulllength RseA ending up in the fragment (Fig. 4B). Continued low-level synthesis of full-length RseA during the course of this experiment may account for the fact that slightly more RseA ends up in the fragment than disappears from the amount of full-length RseA present at any particular time. A precursor-product relationship is also indicated by the fact that upon depletion of YaeL, fulllength RseA disappeared and the RseA fragment appeared (Fig. 1C). Additionally, Kanehara et al. (2002) used a pulse-labeling protocol to demonstrate a precursorproduct relationship. Taken together, these data strongly support the idea that, following induction, DegS processing creates a smaller fragment of RseA, which is subsequently processed by YaeL.

Assuming that the observed RseA fragment does not have an aberrant mobility, it appears to be slightly larger $(>15 \mathrm{kD})$ than the expected size of the cytoplasmic domain alone $(12 \mathrm{kD})$, suggesting that the fragment contains a portion of the transmembrane domain as well as the cytoplasmic domain. We used cellular fractionation and Western blotting to determine the location of the

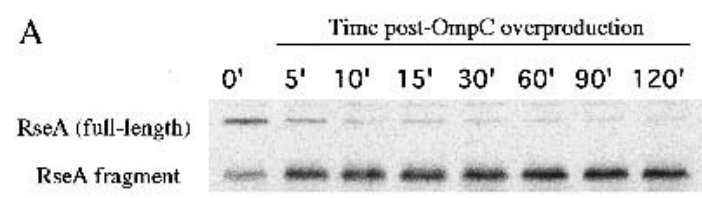

B

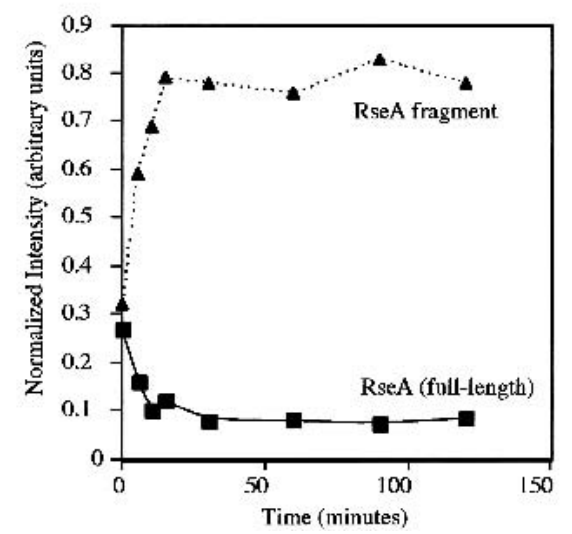

Figure 4. Full-length RseA decreases and the RseA fragment increases following OmpC overexpression. (A) Western blotting (with anti-RseA cytoplasmic domain) of samples harvested from sup $^{+}$yaeL::kanR pompC pJAH340 (yaeL E23A; CAG43541) at various time points after OmpC overexpression is induced. $(B)$ Quantitation of full-length RseA and RseA fragment levels. Blots were quantified as described in Materials and Methods. The intensity of each band was normalized to that of a background band (not shown) to control for loading errors.

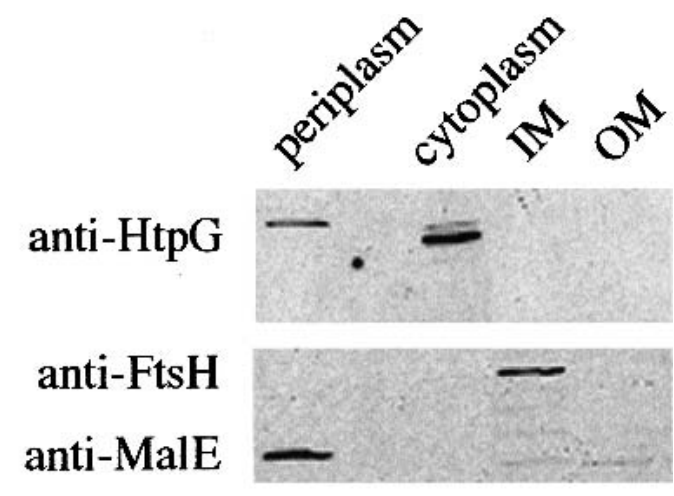

\section{anti-RseA cyto.}

Figure 5. RseA fragment is localized to the inner membrane. Strain sup $^{+}$yaeL ::kanR pompC (CAG43514) was grown to mid$\log$ phase, and pompC was induced with arabinose for $1 \mathrm{~h}$ prior to fractionation, as detailed in Materials and Methods. The cells were fractionated into four components: periplasm, cytoplasm, and inner and outer membrane. Western blots were probed with anti-HtpG (cytoplasmic protein), anti-FtsH (inner membrane protein), anti-MalE (periplasmic protein), and anti-RseA cytoplasmic domain antisera.

RseA fragment (Fig. 5). We found that the RseA fragment was present in the inner membrane fraction and absent from the cytoplasmic, periplasmic, and outer membrane fractions. Control experiments indicated that, as expected, the known inner membrane protease $\mathrm{FtsH} / \mathrm{HflB}$ was present only in the inner membrane fraction and that the cytoplasmic protein HtpG and the periplasmic protein MalE were absent from this fraction. We note that this fragment retained its anti-sigma factor activity (Fig. 2), consistent with previous studies indicating that the cytoplasmic domain of RseA is sufficient for its antisigma activity (De Las Peñas et al. 1997a; Missiakas et al. 1997).

\section{DegS and YaeL are not limiting for $\sigma^{E}$ activity}

Activation of $\sigma^{\mathrm{E}}$ is controlled by a proteolytic cascade. We asked whether the proteases carrying out this function are present in limiting amounts in the cell. We overexpressed DegS and YaeL separately or in combination and saw no increase in the steady-state activity of $\sigma^{\mathrm{E}}$ in the cell (Fig. 6). Western blots confirmed that the accumulation of YaeL and DegS increased upon overexpression (data not shown). These data indicate that simply increasing the amount of these proteases in the absence of stress is not sufficient to induce $\sigma^{\mathrm{E}}$. Instead, an inducing signal that either alters the activity of the proteases or renders RseA accessible to DegS action is required for activation.

\section{Discussion}

The extracytoplasmic stress response in E. coli is controlled by the regulated proteolysis of RseA (Ades et al. 


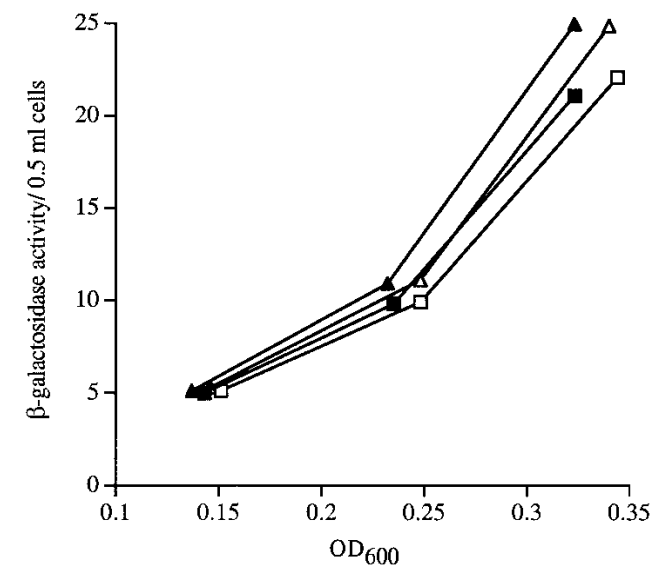

Figure 6. Overexpression of DegS or YaeL separately or together does not affect $\sigma^{\mathrm{E}}$ activity. Wild-type strains with a yaeLexpressing plasmid $\left(\mathbf{\Delta} / \triangle_{;}\right.$CAG43576) or degS-expressing plasmid plus a yaeL-expressing plasmid $(\mathbf{\square} / \square$; CAG43512) were grown to early log phase. At an $\mathrm{OD}_{600} \sim 0.15$, arabinose was added to overexpress $\mathrm{YaeL}$, and $\sigma^{\mathrm{E}}$ activity was by monitored $\beta$-galactosidase assays (See Materials and Methods). DegS was constitutively overexpressed in CAG43512. Solid symbols indicate the $\beta$-galactosidase activity of strains growing in the presence of arabinose (and, hence, overexpressing YaeL); open symbols indicate the $\beta$-galactosidase activity of strains growing in the absence of arabinose (without YaeL overexpression). Strains containing the empty vectors exhibited nearly identical activities and for simplicity are not shown.

1999|, a membrane-spanning anti-sigma factor that sequesters $\sigma^{\mathrm{E}}$, the transcription factor responsible for upregulating expression of the genes involved in this stress response (De Las Peñas et al. 1997a; Missiakas et al. 1997). Upon RseA degradation, $\sigma^{\mathrm{E}}$ is free to associate with RNA polymerase and initiate transcription. The principal finding of the present study is that RseA is degraded by sequential proteolytic events controlled by the integral membrane proteases DegS and YaeL, an ortholog of S2P. The mechanism for activating $\sigma^{\mathrm{E}}$ is remarkably similar to that for activating the mammalian transcription factors ATF6 and SREBP, which control the unfolded protein response and cholesterol homeostasis, respectively.

\section{Rse A is cleaved sequentially by DegS and YaeL}

We have presented evidence that YaeL participates in the degradation of RseA. We first showed that the essential function of YaeL, like that demonstrated previously for DegS (Alba et al. 2001), is to provide $\sigma^{\mathrm{E}}$ activity by participating in the degradation of RseA. We demonstrated this by showing that YaeL is not essential when: (1) a suppressor $\left(\right.$ sup $\left.^{+}\right)$bypasses the need for $\sigma^{\mathrm{E}}$ activity, or (2) the necessity for RseA degradation is bypassed by genetically eliminating RseA from cells. We then showed that DegS functions upstream of YaeL in the degradation pathway. We demonstrated this by following the fate of RseA in sup ${ }^{+}$cells (in which neither YaeL nor DegS is essential) after a $\sigma^{\mathrm{E}}$-inducing signal was provided. In sup ${ }^{+}$ cells expressing DegS and YaeL, degradation of RseA accelerates and proceeds without the accumulation of intermediates upon induction (Ades et al. 1999). DegS is required for initial processing of RseA, because sup ${ }^{+}$cells lacking DegS do not degrade RseA upon induction (Ades et al. 1999|. YaeL is required for a subsequent processing event, because sup $^{+}$cells lacking YaeL rapidly degrade the periplasmic domain upon induction but accumulate the RseA fragment that contains the transmembrane portion and cytoplasmic domain. These data indicate that YaeL processes the RseA fragment generated by DegS action, thereby functioning downstream of DegS in the RseA degradation pathway.

In direct contrast to our finding that YaeL is necessary to activate $\sigma^{\mathrm{E}}$, a recent study found that overexpressing YaeL decreased the activity and amount of $\sigma^{\mathrm{E}}$. The authors of that study concluded that YaeL negatively regulates $\sigma^{\mathrm{E}}$ (Dartigalongue et al. 2001b). Upon YaeL overexpression, we observed no decrease in the activity or amount of $\sigma^{\mathrm{E}}$ in two different $E$. coli strain backgrounds, MC1061 and MG1655 (Fig. 6; data not shown). We also did not observe the decreased $\sigma^{32}$ activity upon YaeL overexpression reported by Dartigalongue et al. 2001b (data not shown). In that study, overexpression of YaeL by arabinose in an $\mathrm{araD}^{-}$background (in which arabinose is toxic; Englesberg et al. 1962) and the use of YaeL overexpression constructs containing a portion of the downstream gene may account for some of these discrepancies. We note that Kanehara et al. (2002) independently reached conclusions similar to ours concerning the role of YaeL in regulating $\sigma^{\mathrm{E}}$ activity.

Pathways for maintaining homeostasis in the E. coli envelope and mammalian ER have a similar means of activation

The envelope of Gram-negative bacteria and the ER of eukaryotes have functional similarities. Both cellular compartments are oxidizing and facilitate disulfide bond formation in proteins. Both compartments are sites of protein folding and assembly. In E. coli, outer membrane proteins and periplasmic proteins fold in the envelope. In eukaryotic cells, all proteins destined for secretion, the ER lumen, or the Golgi are folded in the ER. The compartments are also sites of assembly of membrane components: assembly of the bacterial outer membrane takes place in the envelope, and assembly of lipid bilayers occurs in the ER. Integral membrane transcription factors respond to changing physiological states of the ER and envelope. SREBPs maintain ER lipid homeostasis by responding to the levels of sterols in mammals (Brown and Goldstein 1999) and to phosphatidylethanolamine in Drosophila (Dobrosotskaya et al. 2002). ATF6 responds to changes in ER protein homeostasis by initiating the UPR upon increases in the level of unfolded proteins (Haze et al. 1999). In E. coli, the transcription factor $\sigma^{\mathrm{E}}$, which is indirectly tethered to the membrane via RseA, responds to fluctuations in homeostasis in the envelope. Interestingly, genes whose expressions are controlled by 
$\sigma^{\mathrm{E}}$ overlap the classes of genes whose expressions are controlled by both SREBP (e.g., genes encoding lipid-associated functions) (Brown and Goldstein 1999) and ATF6 (e.g., genes encoding chaperones and protein folding catalysts) (Yoshida et al. 1998). $\sigma^{\mathrm{E}}$ regulates genes important for porin biogenesis and for the production of the lipid A component of the outer membrane (Dartigalongue et al. 2001a; V. Rhodius, W. Suh, S. Ades, C. Onufryk, M. Igo, and C.A. Gross, in prep.). Thus, the $\sigma^{\mathrm{E}}$ pathway regulates the expression of classes of genes that are controlled by at least two separate pathways in higher eukaryotes.

During the ER and envelope responses, proteolysis releases membrane-bound transcription factors so that they can carry out transcription. Proteolysis directly releases the transcription factor domains of SREBP and ATF6 from the membrane so that they can travel to the nucleus and activate transcription (Wang et al. 1994; Sakai et al. 1996; Haze et al. 1999; Ye et al. 2000). Proteolysis indirectly releases $\sigma^{\mathrm{E}}$ by degrading the antisigma factor RseA so that $\sigma^{\mathrm{E}}$ can initiate transcription (Ades et al. 1999). The proteolytic process that releases the three membrane-bound transcription factors is remarkably similar. In each case, the initial processing event is carried out by an integral membrane serine protease. S1P cleaves ATF6 and SREBP in their lumenal domains after transit from the ER to the Golgi (DeBoseBoyd et al. 1999; Ye et al. 2000; Chen et al. 2002), and DegS cleaves RseA in its periplasmic domain. In each case, the second processing event is dependent upon the first and is carried out by a membrane-embedded metalloprotease. Thus, without cleavage at the first site, there is very little cleavage of ATF6 or SREBP by S2P. Likewise, DegS cleavage of RseA is a prerequisite for YaeL cleavage. Finally, in each case, it is the initial processing event that appears to be regulated. For SREBP, an associated regulatory protein (SCAP), which is responsive to sterol levels, causes transit of SREBPs to the Golgi so that they can be cleaved by S1P (DeBose-Boyd et al. 1999; Nohturfft et al. 1999). ATF6 is hypothesized to be escorted to the Golgi in a similar, but SCAP-independent, fashion (Ye et al. 2000; Chen et al. 2002). For RseA, we demonstrate here that the inducing signal promotes the first DegS-dependent cleavage event, even when YaeL is absent.

\section{YaeL and DegS are part of the RseA degradation pathway, whose complete mechanism is undetermined}

Two important issues remain to be addressed before we fully understand the regulated degradation of RseA, which is the major mechanism for regulating the activity of $\sigma^{\mathrm{E}}$. First, what are the molecular details of the DegS and YaeL contributions to the RseA degradation pathway? Second, how do these two proteases cooperate to degrade RseA?

We do not know where DegS cleaves within RseA. Our data indicate that the initial RseA degradation product resulting from DegS activity is a membrane-localized fragment consisting primarily of the cytoplasmic do- main. A VSLG sequence about 30 amino acids downstream from the membrane-spanning region is similar to the VLS sequence at which S1P cuts SREBP-2 (Duncan et al. 1997). A DegS cut at this position would yield a fragment of about $16.7 \mathrm{kD}$, which is consistent with the apparent size of the released RseA fragment we observed. Existing data do not address whether DegS fully degrades the periplasmic domain or allows another periplasmic protease to complete the degradation.

We do not know whether YaeL degrades the cytoplasmic fragment of RseA or simply clips it. YaeL has the protease active-site motifs and hydropathy plot characteristic of S2P. Moreover, our mutational studies indicating that altering the active-site glutamic acid to alanine eliminates protease activity, whereas altering it to aspartic acid slightly reduces activity, are consistent with similar studies in other S2P orthologs. By analogy to S2P (Duncan et al. 1998) and SpoIVFB (Rudner et al. 1999|, we favor the idea that YaeL clips RseA either within or close to the membrane-spanning segment, leaving the cytoplasmic domain associated with $\sigma^{\mathrm{E}}$. In this case, how might the remainder of RseA be degraded so that $\sigma^{\mathrm{E}}$ is released? We note that $\mathrm{S} 2 \mathrm{P}$ cuts at a hydrophobic residue followed by a cysteine, although there is not a stringent preference for the cysteine (Duncan et al. 1998). The RseA transmembrane segment contains a cysteine. If YaeL cuts immediately before the cysteine, it would generate an RseA fragment with a nonpolar tail of GVAA. Nonpolar tails are substrates for the ClpAP and ClpXP proteases, which bind, unfold, and then degrade such substrates (Gottesman et al. 1998). Thus, ClpAP or ClpXP could degrade such a fragment. Because $\sigma^{\mathrm{E}}$ lacks a nonpolar tail, it would not be a substrate of these proteases and would be released during the process of degrading the RseA fragment.

Most importantly, we do not know the functional relationship between DegS and YaeL. The data presented here indicate that whereas DegS can act in the absence of YaeL, the converse is not true. In the absence of YaeL, DegS can both receive an inducing signal and generate a membrane-localized RseA fragment. However, there is no evidence of YaeL function in the absence of DegS, as we do not observe activation of the $\sigma^{\mathrm{E}}$ pathway in response to the OmpC inducing signal. We imagine three possible mechanisms by which DegS can influence YaeL activity. First, DegS cleavage of the periplasmic domain of RseA may alter the membrane-spanning region so that it is accessible to YaeL function, as has been suggested for S1P. In that case, S1P cleavage close to the membrane is thought to alter the conformation of an $\alpha$-helical membrane-spanning segment of SREBP such that the S2P cleavage site is either more accessible or more easily denatured (Ye et al. 2000). Second, DegS might generate a signal that is necessary to activate YaeL. A precedent for this idea comes from investigations of the pathway producing the activated $\sigma^{\mathrm{K}}$ transcription factor required for $B$. subtilis sporulation. Here, the upstream serine peptidase SpoIVB promotes SpoIVFB-dependent processing of the inactive pro- $\sigma^{\mathrm{K}}$ to active $\sigma^{\mathrm{K}}$ by an as yet unknown mechanism (Cutting et al. 1991; Lu et al. 1995; 
Rudner et al. 1999; Wakeley et al. 2000; Hoa et al. 2002). Finally, YaeL might require an interaction with DegS in order to be activated to cleave RseA. Interestingly, both DegS and YaeL have periplasmically localized PDZ domains. In eukaryotes, PDZ domains mediate the building of protein complexes, especially those involved in signal transduction (Harris and Lim 2001). In bacteria, PDZ domains in proteases can mediate substrate recognition (Beebe et al. 2000; Krojer et al. 2002). Interactions between the PDZ domains of DegS and YaeL may alter the activities or substrate recognition properties of YaeL. Mutationally altering or replacing the PDZ domain of YaeL with heterologous sequences inactivates the protein (Dartigalongue et al. 2001b; Kanehara et al. 2001), providing support for the idea that the PDZ domain might play an important role in RseA degradation.

We are continuing to investigate the features of DegS and YaeL that are required for signal transduction in the $\sigma^{\mathrm{E}}$ pathway. Given the mechanistic similarities to the mammalian systems, further study of DegS and YaeL may suggest how two proteases work together to activate membrane-localized transcription factors.

\section{Materials and methods}

\section{Media and antibiotics}

Luria-Bertani (LB) was prepared as described (Sambrook et al. 1989). When required, the media were supplemented with the following: $30 \mu \mathrm{g} / \mathrm{mL}$ kanamycin (Kan); $20 \mu \mathrm{g} / \mathrm{mL}$ chloramphenicol $(\mathrm{Cm})$ (for pBAD33-containing strains) or $10 \mu \mathrm{g} / \mathrm{mL} \mathrm{Cm}$ (for pBAD45-containing strains); $100 \mu \mathrm{g} / \mathrm{mL}$ ampicillin (Ap) or 50 $\mathrm{\mu g} / \mathrm{mL}$ ampicillin (Ap) for CAG43514-based strains. A final percentage of $0.2 \% \mathrm{~L}-(+)$-arabinose was used to induce the expression of yaeL and $\mathrm{ompC}$ from the arabinose-inducible promoter $\mathrm{P}_{\text {ara }}$.

\section{Strains}

Strains used in this study are listed in Table 3. To make the yaeL::kanR strain, JAH175 was transformed with pJAH118 to create JAH152. These clones were then made competent for transformation in the presence of arabinose to induce the lambda phage red/gam genes and the plasmid copy of yaeL. JAH152 was transformed (in the presence of arabinose to induce the complementing yaeL gene on pJAH118) with $50 \mathrm{ng}$ of linear PCR product containing a kanR cassette flanked by regions of homology to the $3^{\prime}$ end of the $c d s A$ gene, found upstream of yaeL, and homology to the $5^{\prime}$ end of yzzN, found immediately downstream of yaeL. The kanR cassette was amplified from FED326 using primers: $y z z / k a n, 5^{\prime}$-GGCGCTGCTAAACAGC AGCGACGCT ATGAGCAACTTTTTCATCGCCATCGTTA TTATGCGTTCTTCCTAACTAACTCtcaTCTGATTAGAAA AACTCATC-3', containing 15 nucleotides (nt) of homology to kanR (bold) plus a stop codon and $77 \mathrm{nt}$ homology to yzzN (underlined); and cds/kan, 5'-ATTGATAGCCTGACGGCTG CGGTACCGGTCTTTGCTTGCTTGTTGTTACTGGTATTC AGGACGCTTtaaCGGAAGGTAATGGGAAAGCCACGTTG TGTC-3', containing $19 \mathrm{nt}$ of homology to kanR (bold) and 66 nt of homology to $c d s A$ (underlined) plus a ribosome binding site and linker. JAH152 transformants that grew on kanamycin were restreaked in the presence of $0.2 \%$ arabinose or $0.2 \%$ glu- cose, and only those grown in the presence of arabinose would restreak, indicating that expression of the complementing copy of yaeL was essential for growth of the newly constructed yaeL::kanR deletion strain. yaeL::kanR was moved into various backgrounds by standard P1 transduction (Miller 1972). When moved into CAG41001 $\left(\sup ^{+}\right)$, the transductants were much smaller and somewhat more heterogeneous than those in the $\Delta r s e A$ and $\Delta \operatorname{deg} S$ backgrounds, although in each case, the transductants were visible after overnight growth at $30^{\circ} \mathrm{C}$.

CAG43540, 43541, and 43553 were made by transforming CAG43514 with pJAH322, pJAH340, and pJAH325, respectively, and selecting on $\mathrm{Ap} / \mathrm{Cm}$. In general, all three strains grew very slowly on selective solid media. CAG43541 and empty vector-containing strains were notably smaller than those of 43540 and 43553 . We noticed some heterogeneity in the colony sizes of transformants, although the heterogeneity was more pronounced among the pJAH340 and empty vector transformants. Therefore, to ensure that our results were not isolatespecific, we tested multiple independent isolates from each transformation in $\sigma^{\mathrm{E}}$ activity assays and for the generation of the RseA fragment. Each strain's respective group of independent isolates exhibited similar phenotypes.

\section{Plasmids}

To make pJAH118 and pJAH184, the yaeL gene was amplified from E. coli MG1655 with the primers YaeL (L), 5'GGAATTCATGCTGAGTTTTCTCTGGGATTTGGC-3', and YaeL (R), 5'-GGAATTCTCATAACCGAGAGAAATCATTG$3^{\prime}$. The product was cloned into EcoRI of each plasmid. To make pBA114, the ompC-containing HinDIII fragment from pEMC1 (Catron and Schnaitman 1987) was cloned into HinDIII of pBAD33. A two-step PCR procedure was used to make pJAH325 (yaeL E23D) and pJAH340 (yaeL E23A). In the first step, two individual PCRs created an overlapping region of homology that contained the desired mutation. The first round of PCR used pJAH184 as a template. For pJAH325, the two individual PCRs were: (1) araC down 5' primer, 5'-GACTAGGCCTGATATAG GCGCCAGCAACCG- $3^{\prime}$, and $3^{\prime}$ primer, $5^{\prime}$ - CAGAAATGACC AAAATCATGCACG-3'; (2) 5'-CGTGCATGATTTTGGTCAT TTCTG-3', and YaeL (R). These two products were gel-purified and, in Step 2, mixed with the outside primers YaeL (L) and YaeL (R), which were then extended across the annealed products from the first round to generate the complete gene. For pJAH340, the first step used (1) araC down and 5'-CAGAAAT GACCAAATGCATGCACG-3'; (2) 5'-CGTGCATGCATTTG GTCATTTCTG-3' and YaeL (R). The second step was like that for pJAH325. The final products were cloned into EcoRI of pDSW206 (Yael E23D) or pDSW204 (YaeL E23A).

\section{Western blotting}

During the course of YaeL depletion (Fig. 1) or during the course of OmpC overexpression (Fig. 4), 900- $\mu \mathrm{L}$ samples were removed and mixed with $100 \mu \mathrm{L}$ of ice-cold $50 \%$ trichloroacetic acid (TCA) and stored on ice. Samples shown in Figure 3 were harvested at $1 \mathrm{~h}$ following the addition of arabinose to overexpress OmpC. TCA precipitates were processed as described in Alba et al. (2001), run on $15 \%$ polyacrylamide gels, and transferred to nitrocellulose. An equal number of cells was loaded for each sample. Western blotting conditions were described previously (Alba et al. 2001). The following dilutions of primary antisera (all rabbit) were used: anti-YaeL (1:5000), anti-RseA cytoplasmic domain (1:5000), anti-HtpG $(1: 10,000)$, and anti-FtsH/MalE mixture $(1: 10,000)$. The secondary antibody (used at $1: 10,000)$ was an anti-rabbit horseradish peroxidase-conjugated antibody from Amersham Life Sciences. Western blots in Figure 4 were 
Table 3. Strains and plasmids used in this study

\begin{tabular}{|c|c|c|}
\hline Strain/plasmid & Relevant genotype & Source/reference \\
\hline \multicolumn{3}{|l|}{ Strain } \\
\hline MC1061 & $\begin{array}{l}\text { araD } \Delta(\text { ara-leu }) 7697 \Delta(\text { codB-lacI }) \text { galK16 } \\
\text { galE15 mcrA0 relA1 rpsL150 spoT1 mcrB9999 hsdR2 }\end{array}$ & $\begin{array}{l}\text { (Casadaban and Cohen 1980); } \\
\quad \text { E. coli Genetic Stock Center }\end{array}$ \\
\hline CAG16037 & MC1061 [ФАrpoH P3::1acZ] & (Mecsas et al. 1993) \\
\hline CAG22216 & 16037 rpoE:: $\Omega \mathrm{Cm}, \mathrm{Cm}^{\mathrm{R}}$ & (Rouvière et al. 1995) \\
\hline CAG22968 & $16037 \Delta$ rseA nadB51::Tn10, Tet $^{\mathrm{R}}$ & this work \\
\hline CAG25187 & $16037 \mathrm{pLC} 245, \mathrm{Ap}^{\mathrm{R}}$ & this work \\
\hline CAG33315 & MC1061 $\Delta \operatorname{degS}[\Phi \lambda r p o H$ P3::1acZ] & (Ades et al. 1999) \\
\hline CAG33330 & 16037 pSU21, $\mathrm{Cm}^{\mathrm{R}}$ & (Alba et al. 2001) \\
\hline CAG33333 & 16037 pLC259, $\mathrm{Cm}^{\mathrm{R}}$ & (Alba et al. 2001) \\
\hline CAG41001 & MC1061 rpoE $E^{+}$with suppressor of $r p o E:: \Omega \mathrm{Cm}$ & (Alba et al. 2001) \\
\hline CAG43471 & 41001 yaeL::kanR, $\operatorname{Kan}^{\mathrm{R}}$ & this work \\
\hline CAG43509 & 16037 yaeL ::kanR pJAH184, $\mathrm{Cm}^{\mathrm{R}} \mathrm{Kan}^{\mathrm{R}}$ & this work \\
\hline CAG43512 & 33333 pJAH118, Ap $^{\mathrm{R}} \mathrm{Cm}^{\mathrm{R}}$ & this work \\
\hline CAG43514 & 43471 pBA114, $\operatorname{Kan}^{\mathrm{R}} \mathrm{Cm}^{\mathrm{R}}$ & this work \\
\hline CAG43540 & 43514 pJAH322, $\mathrm{Cm}^{\mathrm{R}} \mathrm{Ap}^{\mathrm{R}} \mathrm{Kan}^{\mathrm{R}}$ & this work \\
\hline CAG43541 & 43514 pJAH340 $\mathrm{Cm}^{\mathrm{R}} \mathrm{Ap}^{\mathrm{R}} \mathrm{Kan}^{\mathrm{R}}$ & this work \\
\hline CAG43549 & 41001 yaeL::kanR pJAH184, $\mathrm{Cm}^{\mathrm{R}} \mathrm{Kan}^{\mathrm{R}}$ & this work \\
\hline CAG43550 & 22968 yaeL::kanR pJAH184, $\mathrm{Cm}^{\mathrm{R}} \operatorname{Kan}^{\mathrm{R}} \mathrm{Tet}^{\mathrm{R}}$ & this work \\
\hline CAG43551 & 33315 yaeL::kanR pBA114, $\mathrm{Cm}^{\mathrm{R}} \operatorname{Kan}^{\mathrm{R}}$ & this work \\
\hline CAG43552 & 33315 yaeL::kanR pBAD33, $\mathrm{Cm}^{\mathrm{R}} \mathrm{Kan}^{\mathrm{R}}$ & this work \\
\hline CAG43553 & 43514 pJAH325, $\mathrm{Cm}^{\mathrm{R}} \mathrm{Ap}^{\mathrm{R}}$ & this work \\
\hline CAG43560 & 33315 yaeL ::kanR pJAH184, $\mathrm{Cm}^{\mathrm{R}} \operatorname{Kan}^{\mathrm{R}}$ & this work \\
\hline CAG43576 & 33330 pJAH118, $\mathrm{Ap}^{\mathrm{R}} \mathrm{Cm}^{\mathrm{R}}$ & this work \\
\hline KS272 & $\mathrm{F}^{-}$DlacX74 gale galK thi rpsL $\Delta p h o A$ (PvuII) & (Strauch and Beckwith 1988) \\
\hline JAH184 & KS272 pJAH184, $\mathrm{Cm}^{\mathrm{R}}$ & this work \\
\hline JAH301 & JAH184 yaeL ::kanR, $\operatorname{Kan}^{\mathrm{R}} \mathrm{Cm}^{\mathrm{R}}$ & this work \\
\hline JAH175 & KS272 pKOBEG, $\mathrm{Cm}^{\mathrm{R}}$ & this work \\
\hline FED326 & MC1000 dsbD trx $A \Delta(\lambda$ attL-lon $):: \mathrm{pFK} 79\left(\mathrm{pBAD} 18-\mathrm{kan} \Omega \operatorname{trx} A^{+}\right)$ & $\begin{array}{l}\text { F. Katzen, Beckwith lab } \\
\text { (unpubl.) }\end{array}$ \\
\hline \multicolumn{3}{|l|}{ Plasmid } \\
\hline pKOBEG & gam bet exo under $\mathrm{P}_{\text {ara }}$ control, $\mathrm{Cm}^{\mathrm{R}}$ & (Chaveroche et al. 2000) \\
\hline pJAH118 & yaeL in pBAD24, $\mathrm{Ap}^{\mathrm{R}}$ & this work \\
\hline pJAH184 & yaeL in pBAD $45, \mathrm{Cm}^{\mathrm{R}}$ & this work \\
\hline pJAH322 & yaeL in pDSW206, $\mathrm{Ap}^{\mathrm{R}}$ & this work \\
\hline pJAH325 & yaeL E23D in pDSW206, $\mathrm{Ap}^{\mathrm{R}}$ & this work \\
\hline pJAH340 & yaeL E23A in pDSW204, $\mathrm{Ap}^{\mathrm{R}}$ & this work \\
\hline pLC245 & rpoE in $\mathrm{p} \operatorname{Trc99A}, \mathrm{Ap}^{\mathrm{R}}$ & this work \\
\hline pBA114 & ompC in $\mathrm{pBAD} 33, \mathrm{Cm}^{\mathrm{R}}$ & this work \\
\hline pBAD24 & Vector, $\mathrm{pBR} 322$ ori, $\mathrm{P}_{\text {ara }}, \mathrm{Ap}^{\mathrm{R}}$ & (Guzman et al. 1995) \\
\hline pBAD45 & Vector, $\mathrm{p} 15 \mathrm{~A}$ ori, $\mathrm{P}_{\text {ara }} \mathrm{Cm}^{\mathrm{R}}$ & Beckwith lab \\
\hline pDSW204 & Derivative of $\mathrm{p} \operatorname{Trc} 99 \mathrm{~A}, \mathrm{Ap}^{\mathrm{R}}$ & (Weiss et al. 1999) \\
\hline pDSW206 & Derivative of $\mathrm{p} \operatorname{Tr} c 99 \mathrm{~A}, \mathrm{Ap}^{\mathrm{R}}$ & (Weiss et al. 1999) \\
\hline pSU21 & Cloning vector, $\mathrm{p} 15 \mathrm{a}$ ori, $1 a c$ promoter, $\mathrm{Cm}^{\mathrm{R}}$ & (Bartolomé et al. 1991) \\
\hline pTrc99A & Vector, pBR322 ori, $\mathrm{Ap}^{\mathrm{R}}$ & Amersham Pharmacia Biotech \\
\hline
\end{tabular}

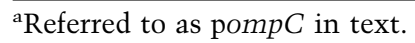

developed with the SuperSignal West Dura Extended Duration Substrate from Pierce. We used the Epi Chemi II Darkroom (UVP Laboratory Products) to capture the light emitted from the blots, and quantitated the bands using the associated software (Labworks). All other Western blots were developed with an enhanced chemiluminescence kit (Amersham Pharmacia Biotech) and exposed to film.

The YaeL antibody was raised in a rabbit (Covance) against a nickel column-purified N-terminally 6His-tagged YaeL periplasmic domain. The coding sequence of the domain, which includes nucleotides 384-1116 (amino acid residues 127-372), was PCR-amplified and cloned into BamHI and HinDIII of pQE30 (QIAGEN).

\section{Genetics addressing yaeL essentiality}

To determine whether yaeL is essential in various backgrounds by using the yaeL depletion strains, efficiencies of plating (EOP) on LB with and without arabinose were performed as follows: 1 $\mathrm{mL}$ of each overnight culture, grown at $30^{\circ} \mathrm{C}$ in $\mathrm{LB} / \mathrm{Cm} /$ arabinose, was pelleted in a microcentrifuge and washed 3 times in 1 $\mathrm{mL} \mathrm{LB}$ to remove arabinose from the suspension. The washed cultures were 10 -fold serially diluted to $10^{-7}$. Ten microliters of dilutions $10^{-1}-10^{-7}$ were spotted onto $\mathrm{LB} / \mathrm{Cm}+/-$ arabinose plates and incubated at $30^{\circ} \mathrm{C}, 37^{\circ} \mathrm{C}$, and $43^{\circ} \mathrm{C}$. EOP values were calculated by dividing the number of colony forming units (cfu) in the absence of arabinose by the number of cfu in the presence of arabinose. Cfu were counted after approximately 20-22 h of 
incubation and did not change upon prolonged incubation. EOP were repeated at least three times, except for CAG43560, which was done twice. Data presented are the average EOP.

P1 transductions using JAH301 as a donor were performed by a standard procedure (Miller 1972). Transductants were selected on LB/Kan or LB/Kan/Ap/+ or - $0.1 \mathrm{mM}$ IPTG (for CAG25187) at $30^{\circ} \mathrm{C}$. Plates were scored after $20-22 \mathrm{~h}$ of growth. CAG41001 yaeL::kanR transductants were much smaller and somewhat more heterogeneous in size than the others.

\section{YaeL depletion in vivo}

CAG43509 was grown at $30^{\circ} \mathrm{C}$ in $\mathrm{LB} / \mathrm{Cm} /$ arabinose to an $\mathrm{OD}_{600}$ of approximately $0.25-0.30$. The culture was poured onto a 0.45 $\mu \mathrm{m}$ Millipore filter (Millipore) in a Nalgene (Nalge Nunc International) filtering system and washed with $10-15 \mathrm{~mL}$ of $30^{\circ} \mathrm{C}$ $\mathrm{LB}$ to remove the arabinose. The cells were resuspended in $30^{\circ} \mathrm{C}$ $\mathrm{LB} / \mathrm{Cm}$ containing arabinose or $0.2 \%$ glucose to an $\mathrm{OD}_{600} \sim 0.04$. At time points after subculturing, aliquots were sampled for Western blots and $\beta$-galactosidase assays. The culture was maintained in exponential growth phase by periodically diluting the culture (to $\mathrm{OD}_{600} \sim 0.04$ ) as follows. An appropriate volume of culture was removed, leaving the subsequent subculture "starter" behind and shaking; the removed volume was quickly replaced with fresh, prewarmed media. We have observed that the alternative dilution method, removing the starter culture by pipet and transferring it to a new flask, can cause a large decrease in $\sigma^{\mathrm{E}}$ activity (S. Ades and B. Alba, unpubl.).

\section{$\beta$-galactosidase assays}

Overnight cultures were diluted to an $\mathrm{OD}_{600} \sim 0.04$ and grown at $30^{\circ} \mathrm{C}$ in LB with the appropriate antibiotics. In experiments involving the overexpression of OmpC (Fig. 2), cultures were grown to $\mathrm{OD}_{600} \sim 0.15$ and sampled for initial $\sigma^{\mathrm{E}}$ activity. Arabinose was then added to induce the overexpression of OmpC. Additional samples were collected at subsequent time points. In Figure 6 , cultures were grown to $\mathrm{OD}_{600} \sim 0.15$, sampled for initial $\sigma^{\mathrm{E}}$ activity, and induced with arabinose to overexpress YaeL; additional samples were collected at subsequent time points. Graphs plot $\beta$-galactosidase activity/sample versus sample $\mathrm{OD}_{600}$, the slope of which is the differential rate of $\beta$-galactosidase synthesis and a measure of $\sigma^{\mathrm{E}}$ activity. Assays were performed as described (Miller 1972; Mecsas et al. 1993; Ades et al. 1999).

\section{Cellular fractionation}

A $10-\mathrm{mL}\left(\mathrm{LB} / \mathrm{Cm} / 30^{\circ} \mathrm{C}\right)$ culture of CAG43514 was grown to $\mathrm{OD}_{600} \sim 0.25$ and induced with arabinose to overexpress OmpC. After $1 \mathrm{~h}$, cells were harvested and fractionated as described in Mecsas et al. (1993). Samples were run on $15 \%$ polyacrylamide gels and analyzed by Western blotting.

\section{Acknowledgments}

We thank Hong Ji Zhong and Grace May Q. Alba for assistance, Jon Beckwith, Beckwith Lab members, and Steve Lory for helpful discussions, and members of the Gross Lab for critically reading the manuscript. This work was supported by U.S. Public Health Service Grant GM36278-18 from the NIH to C.A.G., NIH (NIGMS) grant GM54160 to Jon Beckwith, and a University of California President's Fellowship awarded to B.M.A.
The publication costs of this article were defrayed in part by payment of page charges. This article must therefore be hereby marked "advertisement" in accordance with 18 USC section 1734 solely to indicate this fact.

\section{References}

Ades, S.E., Connolly, L.E., Alba, B.M., and Gross, C.A. 1999 The Escherichia coli $\sigma^{\mathrm{E}}$-dependent extracytoplasmic stress response is controlled by the regulated proteolysis of an antisigma factor. Genes \& Dev. 13: 2449-2461.

Alba, B.M., Zhong, H.J., Pelayo, J.C., and Gross, C.A. 2001. degS $(h h o B)$ is an essential Escherichia coli gene whose indispensable function is to provide $\sigma^{\mathrm{E}}$ activity. Mol. Microbiol. 40: 1323-1333.

An, F.Y., Sulavik, M.C., and Clewell, D.B. 1999. Identification and characterization of a determinant (eep) on the Enterococcus faecalis chromosome that is involved in production of the peptide sex pheromone cAD1. J. Bacteriol. 181: 59155921.

Bartolomé, B., Jubete, Y., Martinez, E., and de la Cruz, F. 1991. Construction and properties of a family of pACYC184-derived cloning vectors compatible with pBR322 and its derivatives. Gene 102: 75-78.

Beebe, K.D., Shin, J., Peng, J., Chaudhury, C., Khera, J., and Pei, D. 2000. Substrate recognition through a PDZ domain in tail-specific protease. Biochemistry 39: 3149-3155.

Betton, J.M., Boscus, D., Missiakas, D., Raina, S., and Hofnung, M. 1996. Probing the structural role of an alpha beta loop of maltose-binding protein by mutagenesis: Heat-shock induction by loop variants of the maltose-binding protein that form periplasmic inclusion bodies. I. Mol. Biol. 262: 140150.

Brown, M.S. and Goldstein, J.L. 1999. A proteolytic pathway that controls the cholesterol content of membranes, cells, and blood. Proc. Nat1. Acad. Sci. 96: 11041-11048.

Brown, M.S., Ye, J., Rawson, R.B., and Goldstein, J.L. 2000 Regulated intramembrane proteolysis: A control mechanism conserved from bacteria to humans. Cell 100: 391-398.

Casadaban, M.J. and Cohen, S.N. 1980. Analysis of gene control signals by DNA fusion and cloning in Escherichia coli. J. Mol. Biol. 138: 179-207.

Catron, K.M. and Schnaitman, C.A. 1987. Export of protein in Escherichia coli: a novel mutation in ompC affects expression of other major outer membrane proteins. J. Bacteriol. 169: 4327-4334.

Chaveroche, M.K., Ghigo, J.M., and d'Enfert, C. 2000. A rapid method for efficient gene replacement in the filamentous fungus Aspergillus nidulans. Nucleic Acids Res. 28: E97.

Chen, X., Shen, J., and Prywes, R. 2002. The luminal domain of ATF6 senses endoplasmic reticulum (ER) stress and causes translocation of ATF6 from the ER to the Golgi. J. Biol. Chem. 277: 13045-13052.

Collinet, B., Yuzawa, H., Chen, T., Herrera, C., and Missiakas, D. 2000. RseB binding to the periplasmic domain of RseA modulates the RseA: $\sigma^{\mathrm{E}}$ interaction in the cytoplasm and the availability of $\sigma^{\mathrm{E}}$ RNA polymerase. J. Biol. Chem. 275: 33898-33904.

Cutting, S., Driks, A., Schmidt, R., Kunkel, B., and Losick, R. 1991. Forespore-specific transcription of a gene in the signal transduction pathway that governs Pro-sigma $\mathrm{K}$ processing in Bacillus subtilis. Genes \& Dev. 5: 456-466. 
Dartigalongue, C., Missiakas, D., and Raina, S. 2001a. Characterization of the Escherichia coli $\sigma^{\mathrm{E}}$ regulon. J. Biol. Chem. 276: 20866-20875.

Dartigalongue, C., Loferer, H., and Raina, S. 2001b. EcfE, a new essential inner membrane protease: Its role in the regulation of heat shock response in Escherichia coli. EMBO J. 20: 5908-5918.

De Las Peñas, A., Connolly, L., and Gross, C.A. 1997a. The $\sigma^{\mathrm{E}}$-mediated response to extracytoplasmic stress in Escherichia coli is transduced by RseA and $\mathrm{RseB}$, two negative regulators of $\sigma^{\mathrm{E}}$. Mol. Microbiol. 24: 373-385.

De Las Peñas, A., Connolly, L., and Gross, C.A. 1997b. $\sigma^{\mathrm{E}}$ is an essential sigma factor in Escherichia coli. J. Bacteriol. 179: 6862-6864.

DeBose-Boyd, R.A., Brown, M.S., Li, W.P., Nohturfft, A., Goldstein, J.L., and Espenshade, P.J. 1999. Transport-dependent proteolysis of SREBP: Relocation of site-1 protease from Golgi to ER obviates the need for SREBP transport to Golgi. Cell 99: 703-712.

Dobrosotskaya, I.Y., Seegmiller, A.C., Brown, M.S., Goldstein, J.L., and Rawson, R.B. 2002. Regulation of SREBP processing and membrane lipid production by phospholipids in Drosophila. Science 296: 879-883.

Duncan, E.A., Brown, M.S., Goldstein, J.L., and Sakai, J. 1997. Cleavage site for sterol-regulated protease localized to a LeuSer bond in the lumenal loop of sterol regulatory elementbinding protein-2. J. Biol. Chem. 272: 12778-12785.

Duncan, E.A., Dave, U.P., Sakai, J., Goldstein, J.L., and Brown, M.S. 1998. Second-site cleavage in sterol regulatory elementbinding protein occurs at transmembrane junction as determined by cysteine panning. J. Biol. Chem. 273: 1780117809.

Dunny, G.M. and Leonard, B.A. 1997. Cell-cell communication in gram-positive bacteria. Ann. Rev. Microbiol. 51: 527-564.

Englesberg, E., Anderson, R.L., Weinberg, R., Lee, N., Hoffee, P., Huttenhauer, G., and Boyer, H. 1962. L-arabinose-sensitive, L-ribulose 5-phosphate 4-epimerase-deficient mutants of Escherichia coli. J. Bacteriol. 84: 137-146.

Gottesman, S., Roche, E., Zhou, Y., and Sauer, R.T. 1998. The ClpXP and ClpAP proteases degrade proteins with carboxyterminal peptide tails added by the SsrA-tagging system. Genes \& Dev. 12: 1338-1347.

Guzman, L.M., Belin, D., Carson, M.J., and Beckwith, J. 1995. Tight regulation, modulation, and high-level expression by vectors containing the arabinose $\mathrm{P}_{\mathrm{BAD}}$ promoter. J. Bacteriol. 177: 4121-4130.

Harris, B.Z. and Lim, W.A. 2001. Mechanism and role of PDZ domains in signaling complex assembly. J. Cell Sci. 114: 3219-3231.

Haze, K., Yoshida, H., Yanagi, H., Yura, T., and Mori, K. 1999. Mammalian transcription factor ATF6 is synthesized as a transmembrane protein and activated by proteolysis in response to endoplasmic reticulum stress. Mol. Biol. Cell. 10: 3787-3799.

Hoa, N.T., Brannigan, J.A., and Cutting, S.M. 2002. The Bacillus subtilis signaling protein SpoIVB defines a new family of serine peptidases. J. Bacteriol. 184: 191-199.

Jones, C.H., Danese, P.N., Silhavy, T.J., and Hultgren, S.J. 1997. The chaperone-assisted membrane release and folding pathway is sensed by two signal transduction pathways. EMBO $J$. 16: 6394-6406.

Kanehara, K., Akiyama, Y., and Ito, K. 2001. Characterization of the yaeL gene product and its S2P-protease motifs in Escherichia coli. Gene 281: 71-79.

Kanehara, K., Ito, K., Akiyama, Y. 2002. YaeL (EcfE) activates the $\sigma^{\mathrm{E}}$ pathway of stress response through a site- 2 cleavage of anti- $\sigma^{\mathrm{E}}$, RseA. Genes \& Dev. (this issue).

Krojer, T., Garrido-Franco, M., Huber, R., Ehrmann, M., and Clausen, T. 2002. Crystal structure of DegP (HtrA) reveals a new protease-chaperone machine. Nature 416: 455-459.

Lewis, A.P. and Thomas, P.J. 1999. A novel clan of zinc metallopeptidases with possible intramembrane cleavage properties. Protein Sci. 8: 439-442.

Lu, S., Cutting, S., and Kroos, L. 1995. Sporulation protein SpoIVFB from Bacillus subtilis enhances processing of the sigma factor precursor Pro- $\sigma^{\mathrm{K}}$ in the absence of other sporulation gene products. J. Bacteriol. 177: 1082-1085.

Mecsas, J., Rouvière, P.E., Erickson, J.E., Donohue, T.J., and Gross, C.A. 1993. The activity of $\sigma^{\mathrm{E}}$, an Escherichia coli heat-inducible $\sigma$, is modulated by the expression of outer membrane proteins. Genes \& Dev. 7: 2618-2628.

Miller, J.H. 1972. Experiments in molecular genetics. pp. 274281. Cold Spring Harbor Laboratory Press, Cold Spring Harbor, NY.

Missiakas, D., Betton, J.M., and Raina, S. 1996. New components of protein folding in extracytoplasmic compartments of Escherichia coli SurA, FkpA and Skp/OmpH. Mol. Microbiol. 21: 871-884.

Missiakas, D., Mayer, M.P., Lemaire, M., Georgopoulos, C., and Raina, S. 1997. Modulation of the Escherichia coli sigmaE (RpoE) heat-shock transcription-factor activity by the RseA, RseB and RseC proteins. Mol. Microbiol. 24: 355-371.

Nohturfft, A., DeBose-Boyd, R.A., Scheek, S., Goldstein, J.L., and Brown, M.S. 1999. Sterols regulate cycling of SREBP cleavage-activating protein (SCAP) between endoplasmic reticulum and Golgi. Proc. Natl. Acad. Sci. 96: 11235-11240.

Pallen, M.J. and Wren, B.W. 1997. The HtrA family of serine proteases. Mol. Microbiol. 26: 209-221.

Patil, C. and Walter, P. 2001. Intracellular signaling from the endoplasmic reticulum to the nucleus: The unfolded protein response in yeast and mammals. Curr. Opin. Cell Biol. 13: 349-355.

Rawson, R.B., Zelenski, N.G., Nijhawan, D., Ye, J., Sakai, J., Hasan, M.T., Chang, T.Y., Brown, M.S., and Goldstein, J.L. 1997. Complementation cloning of S2P, a gene encoding a putative metalloprotease required for intramembrane cleavage of SREBPs. Mol. Cell. 1: 47-57.

Rouvière, P.E., De Las Peñas, A., Mecsas, J., Lu, C.Z., Rudd, K.E., and Gross, C.A. 1995. rpoE, the gene encoding the second heat-shock sigma factor, $\sigma^{\mathrm{E}}$, in Escherichia coli. EMBO J. 14: 1032-1042.

Rouvière, P.E., and Gross, C.A. 1996. SurA, a periplasmic protein with peptidyl-prolyl isomerase activity, participates in the assembly of outer membrane porins. Genes \& Dev. 10: $3170-3182$.

Rudner, D.Z., Fawcett, P., and Losick, R. 1999. A family of membrane-embedded metalloproteases involved in regulated proteolysis of membrane-associated transcription factors. Proc. Natl. Acad. Sci. 96: 14765-14770.

Sakai, J., Duncan, E.A., Rawson, R.B., Hua, X., Brown, M.S., and Goldstein, J.L. 1996. Sterol-regulated release of SREBP-2 from cell membranes requires two sequential cleavages, one within a transmembrane segment. Cell 85: 1037-1046.

Sakai, J., Rawson, R.B., Espenshade, P.J., Cheng, D., Seegmiller, A.C., Goldstein, J.L., and Brown, M.S. 1998. Molecular identification of the sterol-regulated luminal protease that cleaves SREBPs and controls lipid composition of animal cells. Mol. Cell. 2: 505-514.

Sambrook, J., Fritsch, E., and T. Maniatis. 1989. Molecular cloning: A laboratory manual. Cold Spring Harbor Laboratory Press, Cold Spring Harbor, NY.

Strauch, K.L. and Beckwith, J. 1988. An Escherichia coli muta- 
tion preventing degradation of abnormal periplasmic proteins. Proc. Nat1. Acad. Sci. 85: 1576-1580.

Wakeley, P.R., Dorazi, R., Hoa, N.T., Bowyer, J.R., and Cutting, S.M. 2000. Proteolysis of SpolVB is a critical determinant in signalling of Pro- $\sigma^{\mathrm{K}}$ processing in Bacillus subtilis. Mol. Microbiol. 36: 1336-1348.

Waller, P.R.H. and Sauer, R.T. 1996. Characterization of $\operatorname{degQ}$ and $\operatorname{degS}$, Escherichia coli genes encoding homologs of the DegP protease. J. Bacteriol. 178: 1146-1153.

Wang, X., Sato, R., Brown, M.S., Hua, X., and Goldstein, J.L. 1994. SREBP-1, a membrane-bound transcription factor released by sterol-regulated proteolysis. Cell 77: 53-62.

Weiss, D.S., Chen, J.C., Ghigo, J.M., Boyd, D., and Beckwith, J. 1999. Localization of FtsI (PBP3) to the septal ring requires its membrane anchor, the $\mathrm{Z}$ ring, FtsA, FtsQ, and FtsL. I. Bacteriol. 181: 508-520.

Ye, J., Dave, U.P., Grishin, N.V., Goldstein, J.L., and Brown, M.S. 2000. Asparagine-proline sequence within membranespanning segment of SREBP triggers intramembrane cleavage by site-2 protease. Proc. Natl. Acad. Sci. 97: 5123-5128.

Ye, J., Rawson, R.B., Komuro, R., Chen, X., Dave, U.P., Prywes, R., Brown, M.S., and Goldstein, J.L. 2000. ER stress induces cleavage of membrane-bound ATF6 by the same proteases that process SREBPs. Mol. Cell 6: 1355-1364.

Yoshida, H., Haze, K., Yanagi, H., Yura, T., and Mori, K. 1998. Identification of the cis-acting endoplasmic reticulum stress response element responsible for transcriptional induction of mammalian glucose-regulated proteins. Involvement of basic leucine zipper transcription factors. J. Biol. Chem. 273: 33741-33749.

Yu, Y.T. and Kroos, L. 2000. Evidence that SpoIVFB is a novel type of membrane metalloprotease governing intercompartmental communication during Bacillus subtilis sporulation. J. Bacteriol. 182: 3305-3309. 


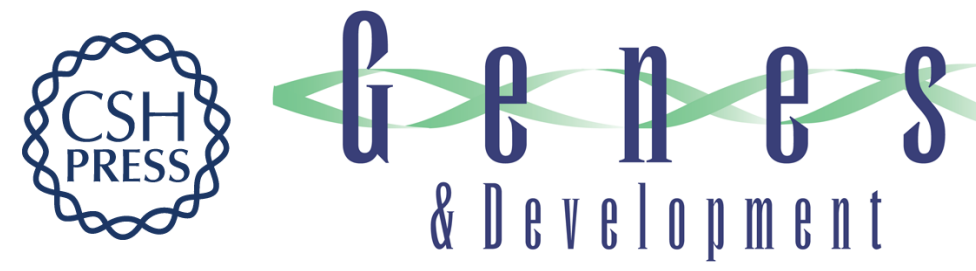

\section{DegS and YaeL participate sequentially in the cleavage of RseA to activate the $\varsigma^{E}$-dependent extracytoplasmic stress response}

Benjamin M. Alba, Jennifer A. Leeds, Christina Onufryk, et al.

Genes Dev. 2002, 16:

Access the most recent version at doi:10.1101/gad.1008902

References This article cites 54 articles, 30 of which can be accessed free at: http://genesdev.cshlp.org/content/16/16/2156.full.html\#ref-list-1

License

Email Alerting Receive free email alerts when new articles cite this article - sign up in the box at the top Service right corner of the article or click here.

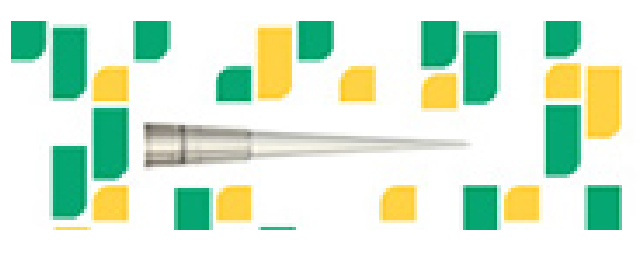

Focused on your science. 